\title{
Research of Associations of Polymorphisms p53 and p21 with the Risk of the Carcinogenesis gastric
}

\author{
AI Dmitrieva ${ }^{1,2}$, NV Sevostyanova ${ }^{2 *}$, VA Serebryakova ${ }^{1,2}$ and AL Chernichova ${ }^{1}$ \\ ${ }^{1}$ Federal State Funded Educational Institution of Higher Education Siberian State Medical University of the Ministry of Healthcare of the Russian Federation, \\ Russia
}

${ }^{2}$ Regional Public Independent Healthcare Institution, Tomsk regional oncologic dispensary, Russia

Received: December 28, 2017; Published: January 08, 2018

*Corresponding author: Sevostyanova Nataliya, Regional Public Independent Healthcare Institution, Tomsk regional oncologic dispensary, Russia, Email: sev_nv@mail.ru

\begin{abstract}
The method of a polymerase chain reaction in the mode of "real time" with hybridizationaly-fluorescent detection carried out the analysis of distribution of polymorphisms of genes p53 by G215C, p21 A1026G and G369C at patients with the gastric carcinoma and healthy donors. It is established that an allele of C, genotypes of CC and GC of polymorphisms G215C of gene p53 and gene G369C p21, an allele of A and genotypes of AA and GA of polymorphism of A1026G of gene p21 statistically are associated with the risk of carcinogenesis gastric.
\end{abstract}

Keywords: p53 G215C; p21 A1026G and G369C; Polymorphism; Regulator genes of a cell cycle; Gastric carcinoma

\section{Introduction}

The Preservation of sustainable growth of gastric carcinoma rates, low detectability at preventive examination, prove the relevance of a problem and prove the need of searching new approaches to prevention and early diagnosis of this tumor. The conception of formation of groups of high oncological risk and carrying out targeted medical examination in these groups, are capable to provide positive dynamics in prevention of malignant tumor of stomach. Variability of the functional activity of the considered genes is caused by a genetic polymorphism [1]. Now more than 30 polymorphisms of a gene p53 are known. The modern researches are devoted generally to assessment of an exonic polymorphism of G215C (changing the amino-acid sequence of protein r53) and polymorphisms in the third (dup16in3duplication of 16 couples of nucleotides) and a pole (replacement of $\mathrm{G}>\mathrm{A}$; of $\mathrm{A}$ in 61 couple of nucleotides) introns [2].

In foreign and domestic researches it is established that an allele C polymorphism of G215C p53 it is associated with the risk of development of ovarian carcinoma [3], carcinoma of lung [2], an alternative genotype-with the increased risk of developing of a breast cancer [4]. Data on existence of associative connection between polymorphic G215C options of the gene p53 and the gastric carcinoma are contradictory. So, H Shen \& coworkers [5] and M Cañas \& coworkers [6] are shown the connection of risk of development of the gastric carcinoma with a carrier statealleleArg. In works of other scientists the association of risk of development of the given oncopathology with carrier state of Pro/Pro genotype at the Korean population [7, 8], and also with a carrier state of genotypes of Arg/Pro + Pro/Pro in the Chinese population [9]. The gene p21 is localized in site 6p.21.2 and represents an inhibitor of the cycline-dependent kinase playing an important role in a stop of a cell-like cycle $[10,11]$.

Results of researches of polymorphic variants of a gene p21 are not numerous and mainly devoted to assessment of one polymorphism of C98A localized in Codonum 31 and causing replacement of Ser by Arg in the amino-acid sequence of protein. In 5 promoter of the gene p21 polymorphic sites of A1026G and G369C which also have the functional value as polymorphisms in the pro-motor sequences are capable to lead to reduction of speed and frequencies of acts of initiation of synthesis of RNA, and as a result, to decrease in an expression of the gene are presented. These literatures concerning the gene expression p21 at tumors of various localizations are ambiguous: the colorectal carcinoma, cervix carcinoma, head and neck carcinoma and small cell carcinoma of lung connect with decrease, and a prostate gland carcinoma and breast cancer, on the contrary, with increase in an expression of the gene of p21 [12].

In Kuznets ova IU [2] research and coworkers it is established that an allele A, the genotype of AA of a polymorphism of A1026G and an allele $\mathrm{C}$ polymorphic variantG369C of the gene p21 are associated with increase in risk of development of carcinoma of lung. In Chen $\mathrm{Z}$ work et al. [6] it is shown that the heterozygous genotype 9T/11T in promoter area of the gene of p21 (rs4135235) 
is potential risk factor for the gastric carcinoma in the Chinese population. The researches devoted to correlation assessment between polymorphisms in the pro-motor region of the gene p21 and the risk of development of the gastric carcinoma in Caucasian population in the modern literature practically do not meet. In this regard essential value assessment of polymorphic variants of regulator genes of a cell cycle p53 G215C and p21 A1026G and G369C at the patients with gastric carcinoma [13]. The goal of research: to estimate distribution of polymorphic variants of genes p53 G215C and p21 A1026G and G369C at the gastric carcinoma [14].

\section{Methodology}

The work is carried out on exemplars of operational material (Histologically the verified locuses of tumoral tissue) 200 patients (75 women and 125 men, average age of $56 \pm 9$ years) with the diagnosis of the gastric carcinoma. The group of comparison was made by 260 healthy donors, with comparable characteristics on gender and age, without oncological pathology, chronic inflammatory processes, and autoimmune, heritable and mental diseases. Considering genetic heterogeneity on p53 and p21 in various populations the research included individuals only of the Caucasian origin. For receiving the genomic of DNA use the commercial set of "FF-PET DNA kit" (Qiagen, Germany) Beforehand carried out dew axing of exemplars of operational material.

DNA from leukocytes of blue blood which was taken away single-passly prior to treatment, allocated with a standard method (set "DNK-sorb-AM", Federal State Institution of Science "CNIE" of Russia Federal Consumer Rights Protection and Human Health Control Service, Moscow). Typing of the allocated DNA samples by polymorphic options of genes r53 G215C, r21 A1026G and G369C carried out by method of a polymerase chain reaction in the mode of "real time" with hybridizationaly-fluorescent detection, using the oligonucleotide of primers and probes [2] corresponding steam. An inspection of a hypothesis of reliability of distinctions between the studied groups was carried out with use of criterion $\chi^{2}$ Pearson (at value of absolute frequencies more than 10) and Fischer's criterion (at value of absolute frequencies less than 5). The association between risk of development of a disease and determined by genotypes was estimated, counting the relation of chances (OR).

\section{Results}

The analysis of polymorphic G215C options of a gene r53 allowed to establish that patients with cancer of a stomach have an occurrence frequency allele C $(23,35 \%)$ was higher $(p=0,001)$, than at healthy faces $(14,62 \%)$. Genotypes of GC and CC $(22,50$ and $12,00 \%$ respectively) at patients with cancer of a stomach were registered on average by 1,6 times more often than in group of monitoring (14,62 and 7,31\% respectively). The risk of development of malignant new growths of a stomach for healthy carriers allele $\mathrm{C}$ polymorphic locus of $\mathrm{G} 215 \mathrm{C}$ of a gene p53 increases in 1,7 (CI95\%1,25-2,51), at GC genotype carriers-in 1,8 (CI95\%1,10-3,07), CC-by 1,9 times (CI95\%0,99-3,90). Studying of distribution of polymorphic G1026A variants of a gene p21 showed that at patients with cancer of a stomach the frequency of occurrence of a homozygous genotype of AA $(15,50 \%)$ exceeded that at healthy faces $(6,54 \%)$ more than twice [15]. Frequency of occurrence "pathological" allele A of a gene p21 was 1,5 times higher than G1026A at patients with the gastric carcinoma, than a similar index at healthy faces (32,25 and 20,96\% respectively).

At healthy individuals of carriers аллеля And polymorphic G1026A option of a gene r21 the risk of development of a carcinoma of the stomach increased by 1,8 times (CI95\%1,32-2,44), at GA genotype carriers-in 1,5 (CI95\%0,96-2,27) and AA genotype-by 3 times (CI95\%1,52-5,99) [16]. The analysis of the polymorphic site of G369C of a gene r21 showed statistically significant increase in frequency of occurrence minor allele $\mathrm{C}$ at patients with cancer of a stomach. Frequency of occurrence of a genotype of CC at patients with cancer of a stomach was 3 times higher, than at healthy faces. Assessment of a risk significance showed that at carriers allele the $\mathrm{C}$ risk of development of a carcinoma of the stomach increased in 1,8 (CI95\%1,25-2,55), a genotype of CC - by 3,3 times (CI95\%1,39$8,18)$.

\section{Conclusion}

Results of the conducted research allow drawing the conclusion that the risk of development of the gastric carcinoma is associated with a carrier stateallele $\mathrm{C}$, genotypes of CC and GC of polymorphic locuses G215C of a gene p53 and gene G369C p21, and also allele A and genotypes of AA and GA of polymorphic A1026G option of a gene $\mathrm{p} 21$. Formation of groups of high oncological risk on the basis of the analysis of polymorphisms of genes p53 G215C, p21 A1026G and G369C will allow to increase considerably effectiveness of oncological medical examination of the population and to improve early diagnostics of the gastric carcinoma.

\section{References}

1. Bellini MF, Cadamuro ACT, Succi M, Proença MA, Silva AE (2012) Alterations of the TP53 Gene in Gastric and Esophageal Carcinogenesis. J Biomed Biotechnol 891961: 1-13.

2. Dmitrieva AI, Serebryakova VA, Kyznetsova IA, Rakitin SS et al. (2014) Identification of polymorphic variants of regulator genes of a cell cycle at carcinoma of lung. Tuberculosis and pulmonary diseases 3: 99-102.

3. Joerger AC, Fersht AR (2007) Structure-function-rescue: the diverse nature of common p53 cancer mutants. Oncogene 26(15): 2226-2242.

4. Schmidt MK, Tommiska J, Broeks A, van Leeuwen FE, Van't Veer LJ, et al. (2009) Combined effects of single nucleotide polymorphisms TP53 R72P and MDM2 SNP 309, and p53 expression on survival of breast cancer patients. Breast Cancer Research 11(6): 89-101.

5. Shen H, Solari A, Wang X, Zhang Z, Xu Y, et al. (2004) P53 codon 72 polymorphism and risk of gastric cancer in a Chinese population. Oncology Reports 11(5): 1115-1120.

6. Cañas M, Morán Y, Camargo ME, Rivero MB, Bohórquez A, et al. (2009) TP53 codon 72 polymorphism and gastric cancer risk: a case-control study in individuals from the central-western region of Venezuela. Investigacion Clinica 50(2): 153-161.

7. Francisco G, Menezes PR, Eluf-Neto J, Chammas R (2011) Arg72 Pro TP53 polymorphism and cancer susceptibility: a comprehensive meta-analysis of 302 case-control studies. International Journal of Cancer 129(4): 920-930.

8. Song HR, Kweon SS, Kim HN, Piao JM, Yun WJ, et al. (2011) p53 codon 72 polymorphism in patients with gastric and colorectal cancer in a Korean population. Gastric Cancer 14(3): 242-248. 
9. Ke-Xiang Z, Yu-Min L, Xun L, Wen-Ce Z, Yong S, et al. (2011) Study on the association of p53 codon 72 polymorphisms with risk of gastric cancer in high incidence Hexi area of Gansu Province in China. Molecular Biology Reports 39(1): 723-728.

10. Kyznetsova IA, Dmitrieva AI, Rakitin SS, Novitskij VV (2012) Polymorphism of regulator genes of a cell cycle p53 and p21WAF1/CIP1 at carcinoma of lung. The Siberian medical magazine 347-353.

11. Chen Z, Dong Y, Wang N, Liang H, Du Y, et al. (2014) A Novel Tri-Allelic Insertion/Deletion Polymorphism in the Promoter of $p 21^{\text {Waff/Cip } 1}$ and the Association with Gastric Cancer. Genet Test Mol Biomarkers 18(2): 112116.

12. Abbas T, Dutta A (2009) p21 in cancer: intricate networks and multiple activities. Nat Rev Cancer 9(6): 400-414.
13. Martinez-Rivera M, Siddik ZH (2012) Resistance and gain-of-resistance phenotypes in cancers harboring wild-type p53. Biochem Pharmacol 83(8): 1049-1062.

14. Saxena A, Shukla SK, Prasad KN, G Uday Chand (2012) Analysis of p53, K-ras gene mutation \& Helicobacter pylori infection in patients with gastric cancer \& peptic ulcer disease at a tertiary care hospital in north India. Indian J Med Res 136(4): 664-670.

15. Schmidt MK, Tommiska J, Broeks A, van Leeuwen FE, Van't Veer LJ, et al. (2009) Combined effects of single nucleotide polymorphisms TP53 R72P and MDM2 SNP 309, and p53 expression on survival of breast cancer patients. Breast Cancer Research 11(6): 89-101.

16. Wang C, Chen Z, Ye Z (2015) Small RNAs inhibit bladder cancer by upregulating tumor suppressor genes. RNA \& disease 2(2): e 595.

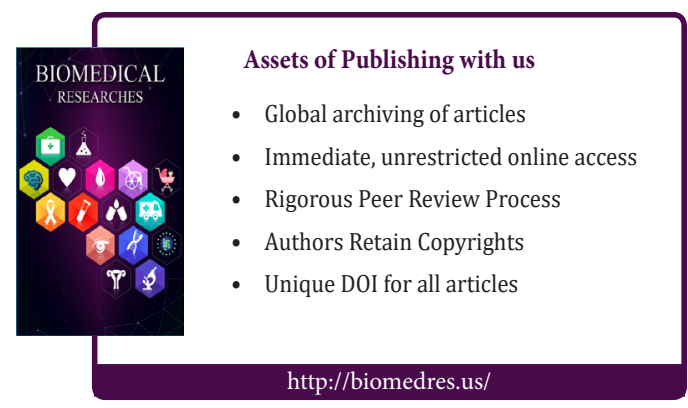

